\title{
Xp pseudoautosomal gene haploinsufficiency and linear growth deficiency in three girls with chromosome Xp22;Yq11 translocation
}

Maries Joseph, Eduardo S Cantú, G Shashidhar Pai, Steven M Willi, Peter R Papenhausen, Lester Weiss

\begin{abstract}
Colony stimulating factor -2 receptor alpha (CSF2RA) and interleukin-3 receptor alpha (IL3RA), two genes from the chromosome $X p$ and $Y p$ pseudoautosomal region (PAR), have been suggested as candidate genes for short stature in Turner syndrome. We report three girls with $X ; Y$ translocation $\quad(46, X, \operatorname{der}(X) t(X ; Y)(p 22$; q11)) initially detected by amniocentesis. The terminal portion of the $X$ chromosome distal to the translocation breakpoint at Xp22 was deleted on the derivative $X$ chromosome in all three patients. Each had normal stature at birth, with greater than expected deceleration of growth velocity by the second year. Using fluorescence in situ hybridisation (FISH), we have shown deletion of the CSF2RA and IL3RA loci on the derivative $X$ chromosomes of all three patients. The role of CSF2RA and IL3RA haploinsufficiency in linear growth and final adult stature is discussed. Additional studies, particularly of molecular deletions within the PAR, are needed to improve our understanding of the role of these and other PAR loci in the genetic control of adult stature.

( $\mathcal{H}$ Med Genet 1996;33:906-911)
\end{abstract}

Division of Genetics and Child

Development,

Department of

Pediatrics, Medical

University of South

Carolina, Charleston,

SC 29425, USA

$M$ Joseph

$S M$ Willi

G S Pai

Department of Pathology and

Laboratory Medicine, Medical University of South Carolina, Charleston, SC, USA E S Cantú

Medical Genetics and Birth Defects Center, Henry Ford Hospital, Detroit, Michigan, USA

L Weiss

Research Triangle Park, NC, USA

P R Papenhausen

Correspondence to: Dr Pai.

Received 5 December 1996 Revised version accepted for publication 10 June 1996

Key words: short stature; pseudoautosomal genes; $\mathrm{X} ; \mathrm{Y}$ translocation; FISH.

Several observations have suggested the probable location of stature controlling gene(s) in the Xp-Yp pseudoautosomal regions (PAR) located at the telomeric ends of the short arms of the $\mathrm{X}$ and $\mathrm{Y}$ chromosomes. ${ }^{1-5}$ The PAR genes escape $\mathrm{X}$ inactivation and hence exert dosage effect. The dosage effect of putative growth gene(s) from this region is further supfrom reference 3 ). ported by the observation that short stature is a consistent clinical finding in Turner syndrome patients and often the only physical manifestation in patients with terminal $\mathrm{Xp}$ deletions, ${ }^{1}$ while tall stature is seen in patients with XXY, XYY, and XXX sex chromosome constitutions. ${ }^{6}$ The study of patients with $\mathrm{X} ; \mathrm{Y}$ chromosomal translocations may help eventually to locate the statural gene(s), since many of these result in deletion of small terminal Xp DNA segments.

CSF2RA and IL3RA are the two most distal genes within the $\mathrm{Xp}$ and Yp PARs, lying within 1180 to $1300 \mathrm{~kb}$ from the Xp and Yp telomeres (fig 1). ${ }^{8}$ Both CSF2 and IL3 are members of the cytokine receptor family and are powerful haemopoietic growth factors that interact with a number of cell types, such as mast cells, megakaryocytes, eosinophils, erythroblasts, pre-B cells and possibly pre-T cells, and osteoclasts. ${ }^{910}$ Pleiotropic effects of these cytokines, stimulating skeletal growth either directly or indirectly, may play a role in linear growth and their haploinsufficiency may explain short stature in Turner syndrome patients. ${ }^{11}$ Here we report the results of our molecular genetic studies to determine the extent of $\mathrm{Xp}$ deletion in three girls with $\mathrm{Xp} 22 ; \mathrm{Yq} 11$ translocations and short stature.

\section{Clinical background} CASE 1

A 2 year old black female with a known X; Y translocation was referred for short stature and premature thelarche. She was born to a 26 year old G1, P0 female whose prenatal course was remarkable for a high maternal serum alphafetoprotein (MSAFP) level at 17 weeks. Amniocentesis showed an abnormal fetal karyotype of $46, \mathrm{X}, \operatorname{der}(\mathrm{X}) \mathrm{t}(\mathrm{X} ; \mathrm{Y})(\mathrm{p} 22 ; \mathrm{q} 11)$.

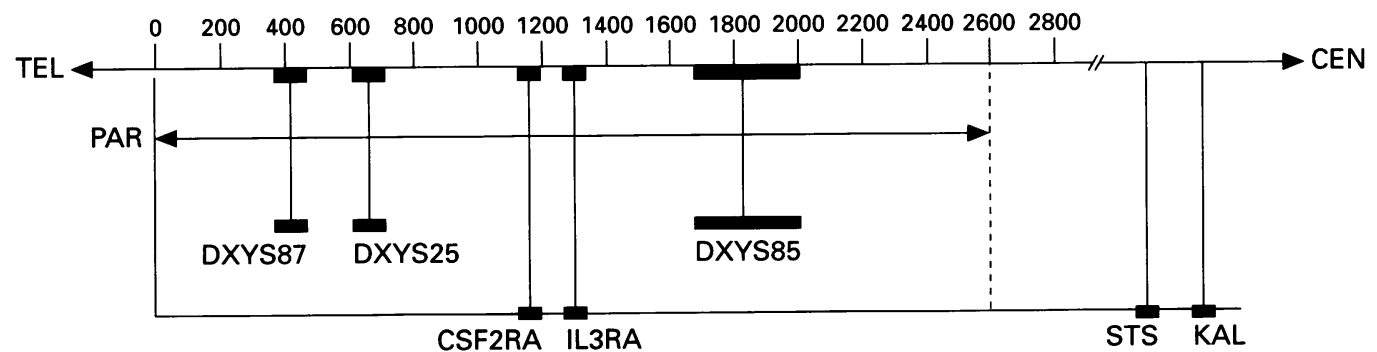

Figure 1 Schematic representation of DNA probes used in this study (CSF2RA, IL3RA, STS, and KAL) relative to $X p$ telomere (TEL), X chromosome centromere (CEN), and other key loci in the Xp pseudoautosomal region (modified 
The mother and two potential fathers were karyotypically normal. Therefore, the fetal karyotypic anomaly was considered to be a de novo occurrence. Family history was unremarkable except for sickle cell trait in her mother and two maternal aunts. Molecular studies of amniocytes showed the presence of the heterochromatic segment from the long arm of the $\mathrm{Y}$ chromosome but absence of the $\mathrm{p}$ arm, centromere, and the sex determining region of the $Y$ (SRY) gene on the derivative $\mathrm{X}$ chromosome. Based on this information, the parents were counselled about the normal female sexual development and the absent risk for gonadoblastoma in the offspring.

A normal female infant was born at term by spontaneous vaginal delivery weighing $2270 \mathrm{~g}$ ( $<5$ th centile) and $47 \mathrm{~cm}$ (15th centile) long. The early neonatal course was unremarkable. She remained essentially healthy except for slight breast development which was first noticed at 3 months of age, progressed over the next 6 months, and then remained static. A decrease in linear growth velocity was noticed during the second year of life. Physical examination at 2 years of age showed a healthy looking toddler with a weight of $8.95 \mathrm{~kg}$ ( $<5$ th centile), a height of $71 \mathrm{~cm}$ ( $<5$ th centile, 50 th centile for age 11 months), and a head circumference of $46 \mathrm{~cm}$ ( 5 th centile). Both motor and language development were normal. Tanner III breast development was noted bilaterally. There was no facial dysmorphism, and normal female external genitalia were noted without pubic hair. Abdominal examination showed no masses and neurological examination was unremarkable. She had one small café au lait spot measuring approximately $0.5 \mathrm{~cm}$ in diameter on her left buttock. Her mother was $155 \mathrm{~cm}$ tall and her father was $162.5 \mathrm{~cm}$ tall giving her an estimated adult height of $152.4 \mathrm{~cm}$ based on her current and midparental heights.

Bone age radiograph showed a skeletal age of 30 months at a chronological age of 23 months. Thyroid function studies were normal. Growth factor profile showed a normal insulin-like growth factor 1 (IGF-1) of $42 \mathrm{ng} / \mathrm{ml}$ (normal range 11-206) and low insulin-like growth factor binding protein 3 (IGFBP3) of $0.9 \mathrm{mg} / 1$ (normal range 1.4-3). Growth hormone (GH) deficiency was confirmed by an abnormal response to a clonidine stimulation test. Gonadal hormone profile showed luteinising hormone (LH) of $<2 \mathrm{mIU} /$ $\mathrm{ml}$, FSH of $3.0 \mathrm{mIU} / \mathrm{ml}$, and oestradiol of $<20 \mathrm{pg} / \mathrm{ml}$, all within the normal range. Her breast tissue development was considered to be premature thelarche. At 26 months of age she was started on growth hormone therapy at a dose of $0.3 \mathrm{mg} / \mathrm{kg} /$ week. Her growth velocity accelerated to $12.1 \mathrm{~cm}$ per year during the first year of therapy which is $2 \mathrm{SD}$ above the normal rate and an expected response for a growth hormone deficient child. At the age of $3 \frac{1}{2}$ years there was once again concern about further breast development. A luteinising hormone releasing hormone (LHRH) stimulation study done at this stage showed normal LHRH response, thus ruling out true precocious puberty. Her growth velocity during the second year of $\mathrm{GH}$ treatment averaged $7.6 \mathrm{~cm}$ per year. Her most recent height at the age of 4 years was on the 30th centile.

CASE 2

Amniocentesis was done on a G2, P1 white female for reasons of advanced maternal age and a previous child with trisomy 21 . Ultrasound examination before amniocentesis had shown a twin pregnancy with female fetuses. Amniotic fluid cell karyotypes were identical and abnormal with both showing 46,X, $\operatorname{der}(\mathrm{X}) \mathrm{t}(\mathrm{X} ; \mathrm{Y})(\mathrm{p} 22.3 ; \mathrm{q} 11.21)$. Normal karyotypes were found for the parents indicating that the $\mathrm{X} ; \mathrm{Y}$ translocation was a de novo rearrangement. Further cytogenetic and molecular studies showed that the $p$ arm, centromere, and the proximal $q$ arm of the $Y$ chromosome were not present on the derivative $\mathrm{X}$ chromosome. Ultrasound examination at 30.3 weeks' gestation suggested that the limbs of the fetuses were at the short end of the normal range with the humerus and femur on the 3 rd centile, radius and ulna on the 10 th centile, and tibia on the 25 th centile.

The monochorionic twins were born without complications at 36 weeks' gestation. Twin 1 had a birth weight of $2300 \mathrm{~g}$ (25th centile), length of $43.2 \mathrm{~cm}$ (5th centile), and head circumference of $32 \mathrm{~cm}$ (25th centile). Twin 2 had a birth weight of $2360 \mathrm{~g}$ (30th centile), a length of $45.7 \mathrm{~cm}$ (25th centile), and a head circumference of $32.3 \mathrm{~cm}$ (40th centile). There were no congenital anomalies noted. Laboratory studies ruled out amino acid and organic acidurias, mucopolysacchariduria, galactosaemia, thyroid disease, biotinidase deficiency, PKU, and G6PD deficiency. Linear growth failure was first appreciated at their 18 month well child examination. Their weight and head circumference were noted to be on the 50th centile while their height was $75 \mathrm{~cm}$ ( $<5$ th centile, 50 th centile for age 1 year). Both twins were also noted to have dolichocephaly, a narrow flat face, downward slanting palpebral fissures, epicanthic folds, and a slightly flat nasal bridge. When last seen at 2 years of age, twin 1 was $81.5 \mathrm{~cm}$ and twin 2 was $81 \mathrm{~cm}$ tall ( $<5$ th centile, 50 th centile for age $1 \frac{1}{2}$ years). Both had weights on the 50th centile. Their development has been completely normal with regard to gross motor, fine motor, and language development. IGF-1 and IGFBP3 levels were within the normal range for age and sex for both twins, ruling out $\mathrm{GH}$ deficiency. Molecular cytogenetic studies were carried out on only one of the twins.

\section{CASE 3}

A 37 year old G4, P2 white female was seen following the detection of a fetal chromosome abnormality during the 21 st week of pregnancy. Amniocentesis was done for advanced maternal age. Fetal karyotype was reported as $46, \mathrm{X}$, $\operatorname{der}(\mathrm{X}) \mathrm{t}(\mathrm{X} ; \mathrm{Y})(\mathrm{p} 22.3 ; \mathrm{q} 11)$. From her first marriage she had a 16 year old son and a 13 year 
Table 1 Results of FISH study in three girls with $X ; Y$ translocation: $46, X, \operatorname{der}(X) t(X$; Y) $(p 22 ; q 11)$

\begin{tabular}{llllll}
\hline Probe & Region & Locus & Case 1 & Case 2 & Case 3 \\
\hline CSF2RA & PAR & Xp22.3 & - & - & - \\
IL3RA & PAR & Xp22.3 & - & - & - \\
STS & Non-PAR & Xp22.3 & - & + & - \\
KAL & Non-PAR & Xp22.3 & + & + & + \\
\hline
\end{tabular}

$-=$ deleted, $+=$ non-deleted.
A total of at least 20 metaphase spreads were scored for each probe used in each case. A normal male control was used to show and compare the normal signals of the CSF2RA and IL3RA loci on the PARs of both Xp and Yp termini. A positive signal was considered as a fluorescent signal present at the expected sites on both chromatids of a metaphase chromosome. If positive signals were present on both the normal $\mathrm{X}$ chromosome and on the derivative $\mathrm{X}$ chromosome, the sample was considered non-deleted for the probe used.

old daughter both in good health. With current husband who is 25 years old, she had one miscarriage before this pregnancy. Further family history was unremarkable. As chromosome analysis was normal for both parents, the fetal karyotypic anomaly was considered to be a de novo event. FISH studies of amniocytes confirmed the absence of the SRY gene and $\mathrm{Y}$ centromeric sequences on the derivative $\mathrm{X}$ chromosome. The parents were counselled regarding normal female sexual development and absent risk for gonadoblastoma in the offspring.

Her prenatal course was unremarkable and the pregnancy ended at term in the birth of a normal female weighing $3400 \mathrm{~g}$ (60th centile) and $53.3 \mathrm{~cm}$ long ( 75 th centile). She had an uneventful neonatal period and has remained healthy with normal psychomotor development. Her length, which was on the 75 th centile at birth, dropped to the 50 th centile by 7 months, and to the 5 th centile at 22 months. Serum IGF-1 and IGFBP3 levels were normal at the age of 24 months providing no evidence of $\mathrm{GH}$ deficiency.

\section{Methods}

High resolution chromosomal GTG banding of cultured, PHA stimulated lymphocytes from peripheral blood was done on cases 1,2 (twin 1 ), and 3 after birth. Additionally, CBG banding was done in cases 2 and 3 and QFQ banding in case 2. Metaphase cells from PHA stimulated lymphocyte cultures of samples from each of the three patients were used for the FISH studies. The four probes studied represent the gene loci for CSF2RA, IL3RA, steroid sulphatase (STS), and Kallmann syndrome in sequential order starting from the Xp telomere (fig 1).

CSF2RA and IL3RA probes were prepared using DNA isolated from the cosmids HO948 and D1O3 obtained from Dr Uta Francke, Stanford University. The DNA probes were labelled in our laboratory with digoxigenin-11dUTP using the nick translation kit (Boehringer Mannheim). The yield of the DIG labelled DNA was estimated by the dot blot assay using Genius 1, 2, and 3 DNA labelling and detection kits (Boehringer Mannheim). Before hybridisation, the labelled probes were ethanol precipitated and dissolved in hybrisol VII (Oncor, Inc). FISH with both CSF2RA and IL3RA probes was also done in a normal control male on separate slides. For the Kallmann (KAL) and steroid sulphatase (STS) loci, commercially available probes were used (Oncor, Inc). Both KAL and STS probes contain $\mathrm{X}$ centromeric sequences to facilitate the identification of the $\mathrm{X}$ chromosome.

\section{Results}

CYTOGENETICS

An abnormal karyotype of $46, X, \operatorname{der}(X) t(X$; $Y)(p 22 ; q 11)$ at a band resolution of 450 to 650 was confirmed in all three girls. Routine GTG banded preparations showed the $\operatorname{der}(\mathrm{X})$ chromosome, which by banding pattern and mor-
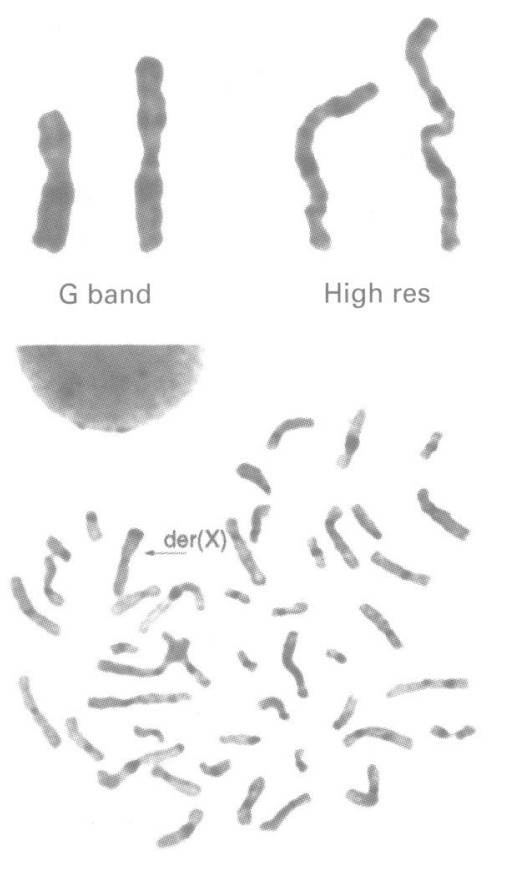

$\mathrm{C}$ banding

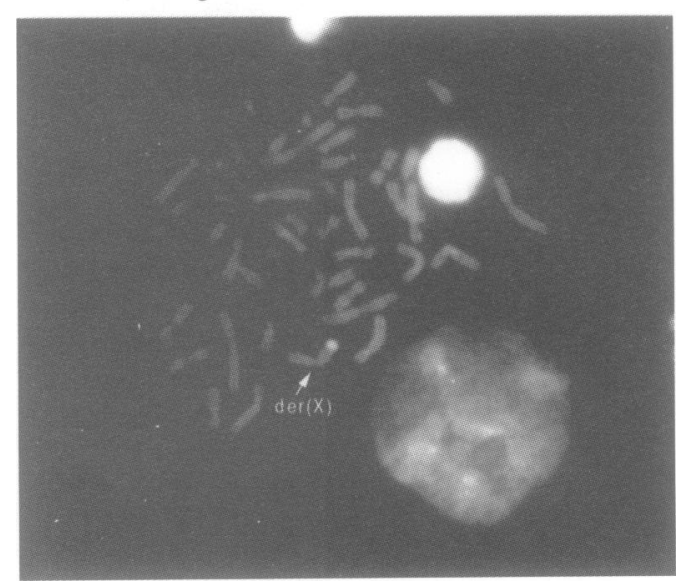

Figure 2 Top panel shows $G$ banded mid and prometaphase $X$ chromosomes of case 2 (the derivative $X$ is on the right in each pair). The middle and bottom panels show representative $C B G$ and $Q F Q$ banded metaphases, respectively; the $\operatorname{der}(X)$ chromosomes show the translocated $Y q$ heterochromatic region on $X p$. 

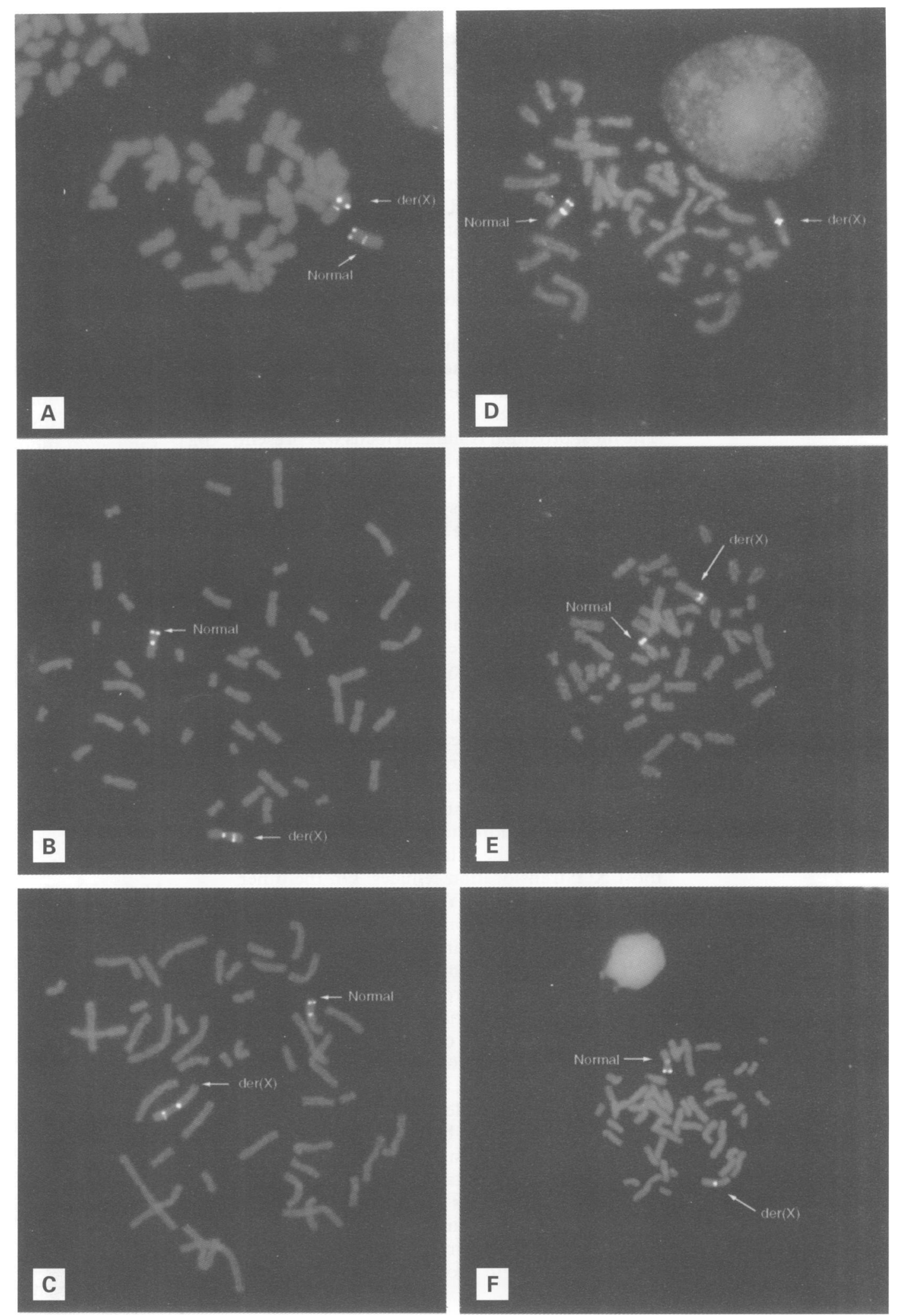

Figure 3 Panel on the left $(A, B, C)$ shows the FISH results using the $K A L$ gene probe in cases 1, 2, and 3 respectively. Positive signals are seen on both the normal and $\operatorname{der}(X)$ chromosomes in each case. Panel on the right $(D$, $E, F)$ represents FISH results with the STS gene probe in cases 1,2 , and 3 respectively. Positive signals are observed on the normal X chromosomes of all three patients and on the $\operatorname{der}(X)$ of only case 2. CSF2RA and IL3RA probes showed positive signals from the normal $X$ of each patient and none of the der(X)s (not shown, see table 1 and text for details).

phology suggested the absence of the $\mathrm{Y}$ chromosome centromere, but the presence of much of the long arm in all three cases. In case 1, additional FISH studies using biotinylated alpha satellite $\mathrm{Y}$ chromosome specific DNA probes and biotinylated $\mathrm{Y}$ classical heterochromatin DNA probe showed the absence of the $\mathrm{Y}$ centromere but presence of the distal heterochromatic block of the $\mathrm{Y}$ chromosome long arm. In cases 2 and 3, CBG banding techniques showed a heterochromatic block on the derivative $\mathrm{X}$ chromosome characteristic of the long arm of the $Y$ chromosome. QFQ banding done in case 2 showed the bright 
heterochromatic block on the derivative chromosome, once again indicative of the long arm of the Y chromosome. Fig 2 shows GTG, CBG, and QFQ banding of the normal $X$ and the derivative $\mathrm{X}$ found in case 2 .

\section{MOLECULAR CYTOGENETICS}

The results of the FISH studies are summarised in table 1 and fig 3. Both CSF2RA and IL3RA loci were found to be deleted on the derivative $\mathrm{X}$ chromosomes of all the three cases, while their normal X chromosomes showed positive signals. The STS locus was found to be deleted on the derivative $\mathrm{X}$ chromosomes of cases 1 and 3 while it was present on the $\operatorname{der}(\mathrm{X})$ chromosome of case 2 . The STS locus was present on the normal X chromosome in all three cases. The most proximal Kallmann locus was present on the normal and derivative $\mathrm{X}$ chromosomes of all three patients. The control male sample showed positive signals for both CSF2RA and IL3RA loci on both the $\mathrm{X}$ and $\mathrm{Y}$ chromosomes.

\section{Discussion}

$\mathrm{X} ; \mathrm{Y}$ chromosomal translocations in humans are classified into three groups based on their phenotypic and karyotypic characteristics: 46, $\mathrm{X}, \mathrm{t}(\mathrm{X} ; \mathrm{Y})$ females, $46, \mathrm{Y}, \mathrm{t}(\mathrm{X} ; \mathrm{Y})$ males, and the rarer $46, X, t(X ; Y)$ males who have the SRY gene on the derivative $\mathrm{X}$ chromosome. ${ }^{1}$ The events leading to $\mathrm{X} ; \mathrm{Y}$ translocation are thought to result from abnormal male meiotic recombination. ${ }^{8}$ Short stature with or without other Turner syndrome stigmata and normal intelligence are the clinical manifestations in most X;Y translocation females. On the other hand, males with $\mathrm{X} ; \mathrm{Y}$ translocation usually have mental retardation in addition to relative short stature. ${ }^{1}$ This is in contrast to XX males with SRY gene translocation and males with XXY Klinefelter syndrome who are usually of normal intelligence and have normal or tall stature. The majority of $46, \mathrm{X}, \mathrm{t}(\mathrm{X} ; \mathrm{Y})$ females represent familial cases who are clinically asymptomatic mothers and sisters of $46, \mathrm{Y}, \mathrm{t}(\mathrm{X}$; $\mathrm{Y})$ phenotypically male probands and have a common translocation breakpoint at $\mathrm{Xp} 22$ and Yq11. ${ }^{1}$ Short stature has been the only consistent clinical abnormality in this group while the few female patients with $\mathrm{X}$; $\mathrm{Y}$ translocation breakpoints more proximal to Xp22 had gonadal dysgenesis or other Turner syndrome stigmata in addition to short stature. ${ }^{1}$

Several other observations have also suggested the possible location of stature controlling genes in the Xp-Yp PAR. Among live born Turner syndrome patients, 50 to $60 \%$ have $45, \mathrm{X}, 20 \%$ have $46, \mathrm{X}, \mathrm{i}(\mathrm{Xq}), 10 \%$ are mosaic $45, X / 46, X X, 7 \%$ have ring(X), and 2 to $3 \%$ have deletions of $\mathrm{Xp} .{ }^{12}{ }^{13}$ Short stature is known to be the most consistent clinical feature of Turner syndrome irrespective of the karyotypic anomalies enumerated above. Deletions of variable lengths of DNA from the short arm of the $\mathrm{X}$ chromosome seem to be a common factor in all of these patients. On the other hand, $\mathrm{Xq}$ arm deletions in females do not appear to exert significant effect on stature. ${ }^{4}$
The presence of a putative growth gene residing in the terminal portion of $\mathrm{Xp}$, the deletion of which decreases the adult height by an average of $12 \mathrm{~cm}$, was suggested by the findings of a family study in which 13 adult females with $46, \mathrm{X}, \operatorname{del}(\mathrm{X})(\mathrm{p} 23)$ in two pedigrees were significantly shorter than their nine $46, \mathrm{XX}$ adult female relatives. ${ }^{2}$ Molecular studies of patients with partial monosomy at the pseudoautosomal region have suggested that a locus affecting height maps to a $1.5 \mathrm{Mb}$ long segment in terminal Xp within the PAR, distal to DXYS85 and proximal to DXYS87 (fig 1). ${ }^{3}$

The $2.6 \mathrm{Mb}$ of DNA in the Xp-Yp PAR constitutes $1.6 \%$ of the human $\mathrm{X}$ chromosome and $3-5 \%$ of the $\mathrm{Y}^{8}$ (fig 3). CSF2RA and IL3RA are the only two known functioning genes from the distal $1.5 \mathrm{Mb}$ of the Xp-Yp PAR, the region thought to harbour the height controlling locus/loci. ${ }^{8}$ Both CSF2 and IL3, along with IL5 and IL13, map to chromosome 5 at $\mathrm{q} 23-\mathrm{q} 31$, within a cytokine family gene cluster. ${ }^{14}$ CSF2 and IL3 share a common beta receptor, the gene for which is mapped to chromosome 22q12.2-q13.1, ${ }^{16}$ while their separate alpha receptors (CSF2RA and IL3RA) lie in close proximity to each other in the $\mathrm{Xp}$ Yp PAR. As the PAR escapes inactivation, a normal male or female should have two doses of functioning CSF2RA and IL3RA genes. CSF2RA and IL3RA, receptors for two potent haematopoietic growth factors, have been suggested as candidate genes for short stature in Turner syndrome. Quantitative studies to document a decreased number of CSF2RA and IL3RA receptors have not been possible in our patients. However, such a decrease is quite likely given the presence of the respective loci on only one of the two homologues. There remains the possibility of as yet undiscovered specific genes responsible for linear growth within the Xp-Yp PAR, possibly distal to the CSF2RA gene. In fact, Ogata et $a l^{45}$ have reported an interesting patient with an inverted duplication of $\mathrm{Xp} 21.3-\mathrm{Xp} 22.33$ with an associated $700 \mathrm{~kb}$ deletion of DNA distal to locus DXSY15. The CSF2RA locus was duplicated on the abnormal $\mathrm{X}$ chromosome in this girl giving her an extra dose of this gene rather than haploinsufficiency. In addition to the loss of as yet unknown stature controlling genes in the deleted segment, the authors suggested the possibility of an abnormal $\mathrm{X}$ inactivation pattern in this derivative chromosome as an explanation for her short stature.

Further evidence for stature controlling genes comes from the demonstration of a GC rich area $470-520 \mathrm{~kb}$ from the telomere within the Xp PAR. ${ }^{8}$ Our three patients are haploinsufficient for this DNA segment as well as the CSF2RA and IL3RA loci. Further characterisation of this DNA region within the $\mathrm{Xp}$ terminus is likely to shed light on the role of the pseudoautosomal genes in the determination of normal adult stature. Similarly, the influence of gene(s) such as GCY on Yq12 that are thought to be influential in adult stature of phenotypic males remains unknown in girls with $\mathrm{Xp}$; Yp translocations. ${ }^{17}$ 
All the three girls in our study had normal body length at birth, suggesting that the linear growth during fetal life and even in first year of life is unaffected by the haploinsufficiency of the growth genes from the PAR. An interesting observation is the impressive response to growth hormone therapy leading to the normalisation of stature (30th centile at age 4 years) in our case 1 , who had GH deficiency shown by appropriate stimulation tests. Similar responses have been noted in Turner syndrome patients with the more common karyotypic abnormalities. Our other two patients had normal GH screening test results and therefore stimulation has not been clinically justifiable. While the effect of GH therapy on the ultimate adult height of our case 1 remains to be established, it is useful to note that the haploinsufficiency of the stature controlling genes in this girl did not interfere with the response to pharmacological doses of $\mathrm{GH}$. The cognitive development of all three of our patients is normal to date. Clinical findings in addition to linear growth deficiency included premature thelarche in case 1 and craniofacial dysmorphic features in case 2 and her twin (not included here). The significance of these observations remains unclear at present.

We would like to thank the parents of our three patients for their cooperation, Dr Karen Keane for providing valuable information on our case 3, and Dr Uta Francke for providing the research probes used in this study.

1 Bernstein R. X;Y chromosome translocation and their manifestations. In: Avery A, Sandberg A, eds. The $Y$ chromosome. Part B. Clinical aspects of $Y$ chromosome mosome. Part B. Clinical aspects of $Y$ chromosom
abnormalities. New York: Alan R Liss, 1985:171-206.
2 Curry CJR, Magenis RE, Brown M, et al. Inherited chondrodysplasia punctata due to a deletion of the terminal short arm of an X chromosome. N Engl f Med 1984;311: $1010-5$.

3 Henke A, Wapenaar M, Ommen G, Maraschio P, Camerino G, Rappold G. Deletions within the pseudoautosomal region help map three new markers and indicate a possible role of this region in linear growth. Am f Hum Genet 1991; 49:811-19.

4 Ogata T, Goodfellow P, Petit C, Aya M, Matsuo N. Short stature in a girl with a terminal Xp deletion distal to DXYS15: localisation of a growth gene(s) in the psueDXYS15: localisation of a growth gene(s) in the

5 Ogata T, Yoshizawa A, Muroya K, et al. Short stature in a girl with partial monosomy of the pseudoautosomal region distal to DXYS15: further evidence for the assignment of the critical region for a pseudoautosomal growth gene(s). f Med Genet 1995;32:831-4.

6 Thompson, Thompson. Genetics in medicine. Philadelphia: Saunders, 1991:239.

7 Ballabio A, Carrozzo R, Gil A, et al. Molecular characterization of human $\mathrm{X} / \mathrm{Y}$ translocation suggests their etiology through aberrent exchange between homologous etiology through aberrent exchange between homologous

8 Rappold GA. The pseudoautosomal regions of the human sex chromosomes. Hum Genet 1993;92:315-24.

9 Gorman DM, Itoh N, Kitamura $\mathrm{T}$, et al. Cloning and expression of a gene encoding an interleukin 3 receptor-like protein: identification of another member of the cytokine receptor gene family. Proc Natl Acad Sci USA 1990;87: 5459-63.

10 Kitamura T, Sato N, Arai KI, Miyajima A. Expression of the human IL 3 receptor cDNA reveals a shared $\beta$ subunit for the human IL-3 and GM-CSF receptors. Cell 1991;66:1165-74.

11 Nusbaum NJ. Turner syndrome as a candidate pseudoautosomal disorder. Med Hypotheses 1992;39:156-8.

12 Lippe B. Turner syndrome. Endocrinol Metab Clin North Am 1991;20:121-58.

13 Massa G, Vanderschueren-Lodeweyckx M, Fryns JP. Deletion of the short arm of the X chromosome: a hereditary letion of the short arm of the X chromosome: a hereditary
form of Turner syndrome. Eur $\mathcal{F}$ Pediatr 1992;151:893-4.

14 McKenzie ANJ, Li X, Largaespada DA, et al. Structural comparison and chromosomal localization of the human comparison and chromosomal localization of the human and mouse

15 Wasmuth JJ, Bishop DT, Westbrook CA. Report of the committee on the genetic constitution of chromosome 5 . Cytogenet Cell Genet 1991;58:261-94.

16 Shen Y, Baker E, Callen DF, et al. Localization of the human GM-CSF receptor $B$ chain gene (CSF2RB) to chromosome 22q12.2-q13.1. Cytogenet Cell Genet 1992; 61:175-7.

17 Ogata T, Tomita K, Hida A, Matsuo N, Nakahori Y, Nakagome Y. Chromosomal localisation of a $\mathrm{Y}$ specific growth gene(s). 7 Med Genet 1995;32:572-5. 